\title{
SELECTIVE MEDIA FOR THE QUANTITATION OF BACTERIA IN CYSTIC FIBROSIS SPUTUM
}

\author{
K. Wong, M. C. Roberts, L. Owens, M. Fife and A. L. Smith \\ Division of Infectious Disease, Children's Orthopedic Hospital and Medical Center, \\ P.O. Box C5371, Seattle, Washington 98105 USA
}

\begin{abstract}
Summary. We used selective media together with aerobic and anaerobic incubation for the quantitation of common pathogens in liquefied sputum from children with cystic fibrosis. The accuracy of the technique was verified by reconstruction studies in which laboratory strains with antibiotic-resistance markers were added to sputum from cystic fibrosis patients. Comparison of the numbers of bacteria found on quantitative culture of clinical specimens with the "predominant" organism found on routine culture yielded a poor correlation. When Pseudomonas aeruginosa was the most prevalent on routine culture, it was present in the highest numbers on quantitative culture (mean count $=10^{8} \mathrm{cfu} / \mathrm{g}$ ). However, large numbers of Haemophilus influenzae (mean count $=10^{7} \mathrm{cfu} / \mathrm{g}$ ), Staphylococcus aureus (mean count $=2 \times 10^{6}$ $\mathrm{cfu} / \mathrm{g}$ ), and streptococci (mean count $=2 \times 10^{6} \mathrm{cfu} / \mathrm{g}$ ) were also present in these cultures. When $S$. aureus was the predominant organism, $H$. influenzae and $P$. aeruginosa were also present in similar numbers $\left(c .10^{7}\right.$ $\mathrm{cfu} / \mathrm{g})$. When $H$. influenzae was the predominant species on routine culture, the mean count was $7 \times 10^{6} \mathrm{cfu} / \mathrm{g}$ and $P$. aeruginosa was often completely absent. We conclude that the selective technique permits reliable enumeration of sputum bacteria, and offers a more accurate assessment of the microbial flora of sputum in cystic fibrosis than does simple plating of unhomogenised sputum.
\end{abstract}

\section{INTRODUCTION}

Pulmonary infection in children with cystic fibrosis is an important factor in the development of progressive pulmonary insufficiency. It is important to identify the bacteria causing the infection so that appropriate antibiotics can be administered.

The bacteria in infected sputum are not uniformly distributed (May 1953; May, Herrick and Thompson, 1972). Thus, correct identification of the predominant organism depends upon sampling an area representative of infection; moreover, expectorated sputum may be contaminated by oropharyngeal bacteria. Pecora (1959) suggested that transtracheal aspiration of sputum from the lower respiratory tract could circumvent the problem of oropharyngeal contamination. However, this 
procedure is not feasible in children with cystic fibrosis. Washing expectorated sputum with saline prior to culture and identification may help to separate true pathogens from upper respiratory tract commensals (Lapinski, Flakas and Taylor, 1964; Bartlett and Finegold, 1978). Alternatively, quantitative sputum cultures may be useful (Louria, 1962). This technique assumes that the infecting bacteria from patients with pneumonia are present in sputum in concentrations that are several hundred-fold greater than in saliva (Monroe et al., 1969).

Kilbourn et al. (1968) introduced a quantitative culture technique for cystic fibrosis sputum. After liquefaction of the sputum, dilutions were plated on media permitting selective growth of gram-negative bacilli and staphylococci. This technique permitted accurate determination of the numbers of certain bacteria (Hammerschlag et al., 1980). However, fastidious organisms such as Streptococcus pneumoniae or Haemophilus influenzae were often difficult to identify in the presence of aerobic gram-negative bacilli. Selective media for these organisms have been developed (Huang, Van Loon and Sheng, 1961; Sondag et al., 1977; Roberts and Cole, 1980) which should improve the isolation rate of these and other potential pathogens.

In this report we describe a quantitative sputum culture procedure using five selective media together with aerobic and anaerobic incubation for the isolation and quantitation of sputum bacteria.

\section{MATERIALS AND METHODS}

Bacterial strains. The reference bacterial strains used were: Pseudomonas aeruginosa PAO 236 (nalidixic acid resistant and non-mucoid) by courtesy of Dr S. Falkow, Stanford University; Haemophilus influenzae $\mathrm{E}_{15}$ (streptomycin and erythromycin resistant) developed in this laboratory; Staphylococcus aureus R549 (methicillin resistant) by courtesy of Dr A. Evans, University of Washington; and Streptococcus pneumoniae R550 (penicillin resistant) by courtesy of Dr L. Tompkins, University of Washington. P. cepacia ATCC strains 10856, 25609, 25608, $P$. maltophilia ATCC13637, $P$. putida ATCC12644, and $P$. alcaligenes ATCC14909 were purchased from the American Type Culture Collection, Rockville, MD. Dr L. Tompkins also supplied two clinical isolates of $P$. cepacia. Twenty-eight noncapsulate $H$. influenzae strains isolated from the sputum of adults were supplied by Dr P. Piot, Antwerp, Belgium. An additional $12 \mathrm{H}$. influenzae type $\mathrm{b}$ strains, isolated from the cerebrospinal fluid of children, were from our own laboratory. All test strains were identified according to standard criteria (Lennette et al., 1980); $H$. influenzae strains were shown to require haemin and $\beta$-nicotinamide adeninedinucleotide for growth on Brain-Heart Infusion Agar (Difco).

Antibiotics. Neomycin and bacitracin (Upjohn, Kalamazoo, MI.), gentamicin (Schering Corp., Bloomfield, NJ.), nalidixic acid (Calbiochem, La Jolla, CA.), methicillin, penicillin G and erythromycin base (Sigma Chemical Corp., St Louis, MO.) and streptomycin (Parke Davis, Detroit, MI.) were obtained from the manufacturers.

Reagents. L-histidine and equine haemin hydrochloride were obtained from Calbiochem Corp., $\beta$-nicotinamide adeninedinucleotide $\left(\mathrm{NAD}^{+}\right)$and ethylhydrocupreine (optochin) were purchased from Sigma Chemical Corp. and sodium dodecylsulphate (SDS) was purchased from Matheson Coleman and Bell, Norwood, Ohio.

Media. Cetrimide agar (Difco) for identification of Pseudomonas and MacConkey agar (Difco) for identification of other gram-negative bacilli were prepared according to the manufacturer's instructions. Blood-agar plates were prepared by adding $5 \%$ sterile sheep blood to autoclaved Trypticase Soy Agar (TSA; BBL). Certain plates were supplemented with gentamicin $10 \mu \mathrm{g} / \mathrm{ml}$ and neomycin $25 \mu \mathrm{g} / \mathrm{ml}$ (BA n/g) to select for streptococci. Modified Brain Heart Infusion Agar (mBHI) was prepared according to the manufacturer's instructions and supplemented with L-histidine $10 \mu \mathrm{g} / \mathrm{ml}$, haemin $10 \mu \mathrm{g} / \mathrm{ml}, \mathrm{NAD}^{+} 10 \mu \mathrm{g} / \mathrm{ml}$ and bacitracin 250 $\mu \mathrm{g} / \mathrm{ml}$ for the selective isolation of Haemophilus spp. 
Mannitol-salt agar plates and Dextrose-soy agar plates containing cycloheximide $400 \mu \mathrm{g} / \mathrm{ml}$ and chloramphenicol $50 \mu \mathrm{g} / \mathrm{ml}$ (DSA c/c) for isolation of yeasts, were purchased from Prepared Media Laboratory, Renton, Washington.

For recovery of antibiotic-resistant reference strains, cetrimide agar was supplemented with nalidixic acid $200 \mu \mathrm{g} / \mathrm{ml}$ (Pseudomonas), BA n/g was supplemented with penicillin G $0.5 \mu \mathrm{g} / \mathrm{ml}$ (Streptococcus), TSA was supplemented with methicillin $20 \mu \mathrm{g} / \mathrm{ml}$ (Staphylococcus) and $\mathrm{mBHI}$ was supplemented with streptomycin $250 \mu \mathrm{g}$ and erythromycin $10 \mu \mathrm{g} / \mathrm{ml}$ (Haemophilus).

Reconstruction experiments. Sputum collected from each of three cystic fibrosis patients during a 12-h period was pooled and the numbers of bacteria were determined by the technique described below. The samples of sputum from these patients were selected on the basis of previous qualitative cultures. One contained $10^{6}$ mucoid $P$. aeruginosa $/ \mathrm{g}$, one contained $10^{6} \mathrm{~S}$. aureus/g and the third pool contained $<200 \mathrm{cfu}$ of $P$. aeruginosa or $S$. aureus/g. Antibiotic resistant $P$. aeruginosa, Str. pneumoniae, $H$. influenzae or $S$. aureus were added to portions of each liquefied pool to achieve a concentration of $10^{6}, 10^{4}$ or $10^{2} \mathrm{cfu} / \mathrm{ml}$ and the samples were mixed by stirring; these samples were then processed by the quantitative technique on antibiotic-supplemented selective media.

Quantitation of sputum bacteria. Dithiothreitol (Sputalysin; Calbiochem) was diluted 1 in 10 with sterile phosphate-buffered saline ( $128.3 \mathrm{~mm} \mathrm{NaCl}, 2.8 \mathrm{mM} \mathrm{KCl}, 0.6 \mathrm{~mm}$ sodium-potassium phosphate, $\mathrm{pH} 7 \cdot 4 \pm 0.05$ ) containing sterile gelatin $0 \cdot 1 \%$ (PBS-G) yielding a final concentration of dithiothreitol $50 \mu \mathrm{g} / \mathrm{ml} ; 0.6 \mathrm{ml}$ of the diluted dithiothreitol was mixed with an equal volume of each sputum sample and the mixture was stirred for $5 \mathrm{~min}$ at room temperature to liquefy the sputum. The homogenate was further diluted 1 in 10,1 in 100 , and 1 in 10000 with PBS-G and $0.1 \mathrm{ml}$ of each dilution was spread with a sterile glass rod on the surface of each of the five media (figure). The appropriate antibiotic-supplemented medium was used for identification and quantitation of the antibiotic-resistant test organisms that had been added to the sputum pools. $\mathrm{BA}(\mathrm{n} / \mathrm{g})$ and $\mathrm{mBHI}$ were incubated anaerobically in a GasPak (BBL) jar to prevent growth of Pseudomonas spp. and to enhance haemolysis by streptococci. All plates were incubated at $37^{\circ} \mathrm{C}$ for $24-48 \mathrm{~h}$. After incubation, organisms were provisionally identified by colonial morphology and colour (Lenette et al., 1980); presumptive confirmation of identity was accomplished by subculture to additional selective media. Two different techniques of subculturing were employed-replica plating and streaking with disposable sterile toothpicks.

Replica plating was by the velvet pad technique (Lederberg and Lederberg, 1952). After aerobic incubation of the replica plate at $37^{\circ} \mathrm{C}$ for $18-24 \mathrm{~h}$, colonial morphology and colour were again used for identification. When there were $>200$ colonies on the primary plate, representative colonies were sampled with toothpicks and streaked in a radial fashion on the secondary selective media.

Gram-stained films were made of organisms growing on the MacConkey and blood agar plates replicated from the $\mathrm{mBHI}$ to verify that they were gram negative and of non-haemolytic colonies growing on the $\mathrm{BA}(\mathrm{n} / \mathrm{g})$ plate to confirm that they were streptococci.

Source of sputum samples. Children with cystic fibrosis seen in the outpatient clinic, or those admitted to hospital for parenteral antibiotic therapy, expectorated into sterile, weighed sputum cups. The samples were immediately transported to the clinical bacteriology laboratory for routine culture after which they were liquefied and cultured by the quantitative technique. To determine the effect of storage, 20 samples whose weight exceeded $2.5 \mathrm{~g}$ were stirred vigorously until they appeared homogeneous, and a $0.5 \mathrm{~g}$ portion was cultured quantitatively. The remainder was stored at $4 \mathrm{C} ; 24$ and $48 \mathrm{~h}$ later, the refrigerated specimen was again cultured to determine the effect of storage on the density of viable organisms. Ninety-nine consecutive sputum samples were collected; 60 were also processed in the routine clinical bacteriology laboratory to compare the quantitative technique to routine culture.

\section{RESULTS}

This investigation concentrated on the isolation of $P$. aeruginosa, S. aureus, Str. pneumoniae and $H$. influenzae because they are the chief pulmonary pathogens in 
Step 1: Homogenise sputum with dithiothreitol (Sputalysin)

Step 2: Dilute 1 in 10,1 in 100 and 1 in 10000

Step 3: Plate $0.1 \mathrm{ml}$ of undiluted homogenate and of each dilution on to:*

(i) Cetrimide agar - growth = Pseudomonas $\mathrm{sp}$.

(ii) Blood agar $(\mathrm{n} / \mathrm{g}) \quad-\alpha$-haemolysis $=S t r$. pneumoniae or viridans streptococci (incubate anaerobically)

(iii) mannitol salt agar

$-\beta$-haemolysis $=\beta$-haemolytic streptococci or staphylococci - no haemolysis = non-haemolytic streptococci, staphylococci, - yellow $=S$. aureus or yeast gram-negative bacilli or yeast

(iv) Modified BHI agar (incubate anaerobically)

- pink $=S$. epidermidis

- growth $=H$. influenzae etc.

(v) Dextrose soy agar $(\mathrm{c} / \mathrm{c}) \quad$-growth = Candida $\mathrm{sp}$.

Step 4: Confirm identity of isolates with gram-film and supplementary tests as necessary

* A MacConkey agar plate should be included for specimens from patients suspected of harbouring Enterobacteriaceae.

FIG.-Steps for processing cystic fibrosis sputum for quantitative culture of common bacteria after overnight incubation at $37^{\circ} \mathrm{C}$. Preliminary identification is made on the basis of colonial morphology.

patients with cystic fibrosis (Huang et al., 1961; Iacocca, Sibinga and Barbero, 1963). Cetrimide plates were relatively specific for the growth of $P$. aeruginosa. P. putida produced small $(1.0 \mathrm{~mm}$ diam.), faintly yellow, opaque colonies that had a thick "buttery" consistency. All five strains of $P$. cepacia grew on cetrimide plates but produced small $(<1.0 \mathrm{~mm}$ diam.) opaque white colonies with an ammoniacal odour. $P$. alcaligenes and $P$. maltophilia did not grow on cetrimide agar. There was delayed growth of $P$. aeruginosa from sputum cultures obtained from patients receiving antibiotics active against that species; in 27 of 37 consecutive isolates, growth on cetrimide agar was evident only after incubation for $48 \mathrm{~h}$. None of the Pseudomonas spp. grew anaerobically on the supplemented BHI agar.

Sixty-three $S$. aureus isolates identified by a positive coagulase test produced yellow colonies, 1-2 mm diam., on mannitol salt agar after incubation for $48 \mathrm{~h}$ at $37^{\circ} \mathrm{C}$. $S$. epidermidis (coagulase negative) produced small, dry, pink colonies on mannitol salt agar. Of 60 consecutive sputum cultures plated on this media, low numbers $\left(<10^{2} \mathrm{cfu} / \mathrm{g}\right)$ of a small gram-positive coccus that appeared as large, pink mucoid colonies grew from two. These organisms were subsequently identified as micrococci.

Blood agar supplemented with neomycin and gentamicin inhibited the growth of most oropharyngeal gram-positive and gram-negative genera other than streptococci. Anaerobic incubation made it easier to identify the species by enhancing haemolysis (Sondag et al., 1977).

For $\alpha$-haemolytic streptococci, growth on ethylhydrocupreine $5 \mu \mathrm{g} / \mathrm{ml}$ or sodium dodecyl sulphate $1 \%$ was used to differentiate viridans streptococci from $S t r$. pneumoniae. Typing sera were used to group the $\beta$-haemolytic streptococci. Further identification of $\alpha$-haemolytic streptococci was not undertaken.

Brain heart infusion agar supplemented with bacitracin and incubated anaerobically was highly selective for $H$. influenzae. All other organisms that grew on this medium could be distinguished from $H$. influenzae by colony size ( $\geq 2 \mathrm{~mm}$ diam.) and consistency (smooth to mucoid); all such bacteria grew aerobically on MacConkey agar and were Escherichia coli, Enterobacter spp. or Klebsiella pneumoniae. 
TABLE I

Recovery of bacteria by quantitative culture of reconstructed sputum

\begin{tabular}{l|ccc}
\hline & \multicolumn{3}{|c}{ Percentage recovery when the inoculum contained } \\
\cline { 2 - 4 } Test species & $10^{6} \mathrm{cfu} / \mathrm{ml}$ & $10^{4} \mathrm{cfu} / \mathrm{ml}$ & $10^{2} \mathrm{cfu} / \mathrm{ml}$ \\
\hline P. aeruginosa & 100 & 80 & 82 \\
Sir. pneumoniae & 100 & 100 & 82 \\
H. influenzae & 95 & 94 & 94 \\
S. aureus & 100 & 100 & 97 \\
\hline
\end{tabular}

\section{Reconstruction experiments}

The three sputum pools gave similar recovery rates for all four organisms. Therefore, all three results were combined (table I). For sputum seeded with $10^{6}$ organisms $/ \mathrm{g}$, there was $95-100 \%$ recovery of each organism. At a density of $10^{2}$ organisms $/ \mathrm{g}$, the recovery rate was lower, but still greater than $80 \%$. Similar recovery rates were found with each of the organisms tested. All $40 \mathrm{H}$. influenzae strains tested grew anaerobically on the BHI-bacitracin agar; incubation for 36-48 h was necessary for the typical morphology to be apparent.

There was no detectable change in the numbers of $S$. aureus, $P$. aeruginosa, $H$. influenzae and Str. pneumoniae isolated after storage for 2 days at $4{ }^{\circ} \mathrm{C}$; longer storage conditions were not tested.

\section{Clinical specimens}

The results of quantitative culture and direct plating of unhomogenised sputum were strikingly different (table II). For the 60 sputum samples examined, there was little relationship between the predominant organism isolated on routine culture, and the number of each species isolated on selective media by the quantitative method. However, certain trends were evident. When $H$. influenzae was detected as the primary isolate on routine culture, small numbers of $P$. aeruginosa were isolated by the quantitative technique, although $H$. influenzae was more numerous. When $P$. aeruginosa was the predominant organism on routine culture, it was also most numerous on quantitative culture; however, the presence of $P$. aeruginosa did not

\section{TABLE II}

Comparison of routine and quantitative culture of sputum from children with cystic fibrosis

\begin{tabular}{|c|c|c|c|c|c|}
\hline \multirow{2}{*}{$\begin{array}{l}\text { "Primary organism" } \\
\text { on routine culture }\end{array}$} & \multirow{2}{*}{$\begin{array}{c}\text { Number } \\
\text { of } \\
\text { specimens }\end{array}$} & \multicolumn{4}{|c|}{ Mean number of cfu (range)/g of sputum of } \\
\hline & & P. aeruginosa & H. influenzae & S. aureus & streptococcus \\
\hline$P$. aeruginosa & 22 & $\begin{array}{c}1 \times 10^{8} \\
\left(4 \times 10^{4}-8 \times 10^{8}\right)\end{array}$ & $\begin{array}{c}1 \times 10^{7} \\
\left(3 \times 10^{6}-7 \times 10^{7}\right)\end{array}$ & $\begin{array}{c}2 \times 10^{6} \\
\left(5 \times 10^{5}-1 \times 10^{7}\right)\end{array}$ & $\begin{array}{c}1 \times 10^{6} \\
\left(4 \times 10^{2}-6 \times 10^{6}\right)\end{array}$ \\
\hline H. influenzae & 4 & $\begin{array}{c}5 \\
(0-22)\end{array}$ & $\begin{array}{c}7 \times 10^{6} \\
\left(4 \times 10^{3}-3 \times 10^{7}\right)\end{array}$ & $\begin{array}{c}1 \times 10^{5} \\
\left(1 \times 10^{4}-5 \times 10^{5}\right)\end{array}$ & $\begin{array}{c}7 \times 10^{5} \\
\left(8 \times 10^{4}-2 \times 10^{6}\right)\end{array}$ \\
\hline S. aureus & 18 & $\begin{array}{c}4 \times 10^{4} \\
\left(2 \times 10^{3}-1 \times 10^{8}\right)\end{array}$ & $\begin{array}{c}1 \times 10^{7} \\
\left(2 \times 10^{5}-1 \times 10^{8}\right)\end{array}$ & $\begin{array}{c}1 \times 10^{7} \\
\left(2 \times 10^{5}-4 \times 10^{7}\right)\end{array}$ & $\begin{array}{c}2 \times 10^{5} \\
\left(2 \times 10^{4}-8 \times 10^{6}\right)\end{array}$ \\
\hline streptococci & 16 & $\begin{array}{c}1 \times 10^{5} \\
\left(2 \times 10^{2}-6 \times 10^{8}\right)\end{array}$ & $\begin{array}{c}5 \times 10^{5} \\
\left(5 \times 10^{4}-3 \times 10^{6}\right)\end{array}$ & $\begin{array}{c}2 \times 10^{5} \\
\left(8 \times 10^{3}-1 \times 10^{6}\right)\end{array}$ & $\begin{array}{c}2 \times 10^{6} \\
\left(2 \times 10^{4}-8 \times 10^{6}\right)\end{array}$ \\
\hline
\end{tabular}


exclude large numbers of $H$. influenzae $\left(10^{7} \mathrm{cfu} / \mathrm{g}\right), S$. aureus $\left(10^{6} \mathrm{cfu} / \mathrm{g}\right)$ and streptococci $\left(10^{6} \mathrm{cfu} / \mathrm{g}\right)$.

Streptococci were isolated from every sputum sample, and were present in slightly higher numbers $\left(10^{6}\right.$ versus $\left.10^{5}\right)$ when they were identified as the "primary organism" on routine culture. Only 12 out of 73 streptococci isolated were Str. pneumoniae and numbers of this species did not exceed $10^{4} \mathrm{cfu} / \mathrm{g}$. In contrast, quantitative culture of the 60 consecutive sputum samples yielded $S$. aureus (15 samples), $P$. aeruginosa (16 samples), and $H$. influenzae (6 samples) in concentrations $\geq 10^{5} \mathrm{cfu} / \mathrm{g}$. Sixteen samples contained $\geq 10^{5} \mathrm{cfu} / \mathrm{g}$ of $S$. aureus and $P$. aeruginosa.

\section{Discussion}

The technique described by Kilbourn et al. (1968) took account of the non-uniform distribution of bacteria in sputum and used two selective media for identification of Staphylococcus spp. and gram-negative bacilli. More recently, George, Gillett and Roycroft (1980) and Roberts and Cole (1980) noted that, in the presence of Pseudomonas spp., other species, particularly of the genera Haemophilus or Streptococcus, were rarely isolated. As a result, selective techniques were devised for the isolation of streptococci or Haemophilus spp. in the presence of Pseudomonas spp.

We have combined dithiothreitol liquefaction and dilution to quantitate sputum bacteria and have used five selective media together with aerobic and anaerobic incubation to facilitate isolation. The media were chosen to identify the organisms most commonly isolated from sputum in cystic fibrosis: $S$. aureus, Pseudomonas spp., H. influenzae, streptococci, Proteus spp., yeasts or coliform bacilli (Feigelson and Pecau, 1967; Huang et al., 1961; Iacocca et al., 1963). Although the aminoglycosidesupplemented blood agar plate had the potential to grow the greatest number of bacteria, we found the number of genera other than Streptococcus limited.

We feel that this method reliably quantitates the organisms most commonly found in sputum from children with cystic fibrosis, and offers additional information in comparison to the standard plating method. Future studies will determine the value of quantitative sputum cultures in children with cystic fibrosis.

These studies were supported in part by the Cystic Fibrosis Foundation and GM26550.

\section{REFERENCES}

Bartlett J G, Finegold S M 1978 Bacteriology of expectorated sputum with quantitative culture and wash technique compared to trans-tracheal aspirates. American Review of Respiratory Disease 117:1019-1027.

Feigelson J, Pecau Y 1967 Bacteriological studies of bronchial secretions in 19 cases of cystic fibrosis. Modern Problems in Pediatrics 10:214-226.

George R H, Gillett A P, Roycroft C A 1980 Haemophilus infections in cystic fibrosis. Lancet $2: 262$.

Hammerschlag M R, Harding L, Macone A, Smith A L, Goldmann D A 1980 Bacteriology of sputum in cystic fibrosis: Evaluation of dithiothreitol as a mucolytic agent. Journal of Clinical Microbiology 11:552-557.

Huang N N, Van Loon E L, Sheng K T 1961 The flora of the respiratory tract of patients with cystic fibrosis of the pancreas. Journal of Pediatrics 59:512-521.

Iacocca V F, Sibinga M, Barbero G J 1963 Respiratory tract bacteriology in cystic fibrosis. American Journal of Diseases of Children 106:315-324. 
Kilbourn J P, Campbell R A, Grach J L, Willis M D 1968 Quantitative bacteriology of sputum. American Review of Respiratory Disease 98:810-818.

Lapinski E M, Flakas E D, Taylor B C 1964 An evaluation of some methods for culturing sputum from patients with bronchitis and emphysema. American Review of Respiratory Disease 89:760-763.

Lederberg J, Lederberg E M 1952 Replica plating and indirect selection of bacterial mutants. Journal of Bacteriology 63:399-406.

Lennette E H, Balows A, Hausler W J, Truant J P 1980 Manual of clinical microbiology, 3rd edn. American Society for Microbiology, Washington DC.

Louria D B 1962 Uses of quantitative analyses of bacterial populations in sputum. Journal of the American Medical Association 182:1082-1086.

May J R 1953 The bacteriology of chronic bronchitis. Lancet 2:534-537.

May J R, Herrick N C, Thompson D 1972 Bacterial infection in cystic fibrosis. Archives of Disease in Childhood 47:908-913.

Monroe P W, Muchmore H G, Felton F G, Pirtle J K 1969 Quantitation of microorganisms in sputum. Applied Microbiology 18:214-220.

Pecora D V 1959 A method of securing uncontaminated tracheal secretions for bacterial examination. Journal of Thoracic Surgery 37:653-654.

Roberts D E, Cole P 1980 Use of selective media in bacteriological investigation of patients with chronic suppurative respiratory infection. Lancet 1:796-797.

Sondag J E, Morgens R K, Hoppe J E, Marr J J 1977 Detection of pneumococci in respiratory secretions: Clinical evaluation of gentamicin blood agar. Journal of Clinical Microbiology 5:397-400. 